\title{
Timing and Significance of Exercise-Induced Left Ventricular Outflow Tract Pressure Gradients in Hypertrophic Cardiomyopathy
}

\author{
Stefano Nistri, MD ${ }^{\mathrm{a}, \mathrm{b}, *}$, Iacopo Olivotto, MD ${ }^{\mathrm{b}}$, Martin S. Maron, MD ${ }^{\mathrm{c}}$, Camilla Grifoni, $\mathrm{MD}^{\mathrm{b}}$, \\ Katia Baldini, $\mathrm{RN}^{\mathrm{b}}$, Massimo Baldi, MD ${ }^{\mathrm{b}}$, Aurelio Sgalambro, MD ${ }^{\mathrm{b}}$, Franco Cecchi, $\mathrm{MD}^{\mathrm{b}}$, and \\ Barry J. Maron, MD ${ }^{\mathrm{d}}$
}

\begin{abstract}
The relation of exercise-induced left ventricular (LV) outflow tract obstruction to functional capacity in hypertrophic cardiomyopathy (HC) is incompletely defined. Thus, we assessed the patterns of onset of physiologically provoked LV outflow gradients and exercise performance in 74 consecutive patients with $\mathrm{HC}$ (age $45 \pm 16$ years; $74 \%$ men) without LV outflow obstruction at rest. The subaortic gradients were measured serially using echocardiography in these 74 patients during maximum, symptom-limited, upright bicycle exercise testing. The time course of the provoked gradients and the relation to exercise performance were assessed. Of the 74 patients, $30(41 \%)$ developed a dynamic LV outflow gradient of $\geq 30 \mathrm{~mm} \mathrm{Hg}$ (mean $78 \pm 37 \mathrm{~mm} \mathrm{Hg}$ ) during upright exercise testing that correlated highly with the gradients measured with the patients supine during the immediate recovery period $\left(\mathrm{R}^{2}=0.97\right)$. The 16 patients in whom outflow obstruction developed rapidly at low exercise levels ( $\leq 5$ METs) had a significantly reduced exercise capacity $(6.1 \pm 1.3$ vs $8.0 \pm 1.6$ METs; $p<0.01)$ compared to the other 14 patients in whom obstruction appeared later at greater exercise levels of $>5$ METs. The timing of the gradient onset was not predictable from the baseline clinical and echocardiographic features, peak exercise LV outflow tract gradient, or symptoms. In conclusion, in patients with $\mathrm{HC}$ without outflow obstruction at rest, the earlier onset of LV outflow tract gradients during physiologic exercise was associated with impaired exercise performance. These findings have provided insights into the determinants of functional impairment in $\mathrm{HC}$ and support the potential value of exercise echocardiography in the clinical assessment of patients with HC. (C) 2010 Elsevier Inc. All rights reserved. (Am J Cardiol 2010;106:1301-1306)
\end{abstract}

Left ventricular (LV) outflow obstruction under resting conditions represents an important determinant of progressive heart failure-related disability in patients with hypertrophic cardiomyopathy (HC). ${ }^{1,2}$ Furthermore, a significant proportion of patients with $\mathrm{HC}$ without obstruction at rest will develop substantial outflow gradients during physical exertion, 3,4 the clinical significance of which is unresolved. ${ }^{5,6}$ Previous studies of inducible obstruction in patients with $\mathrm{HC}$ have focused largely on single measurements, often obtained at peak or immediately after exercise, the latter generally measured with the patient in the supine

${ }^{\mathrm{a} C M S R-V e n e t o ~ M e d i c a, ~ A l t a v i l l a ~ V i c e n t i n a ~(V I), ~ I t a l y ; ~}{ }^{\mathrm{b}}$ Regional Referral Center for Myocardial Diseases, Azienda Ospedaliera Careggi, Florence, Italy; 'Hypertrophic Cardiomyopathy Center, Division of Cardiology, Tufts-New England Medical Center, Boston, Massachusetts; ${ }^{\mathrm{d}}$ Hypertrophic Cardiomyopathy Center, Minneapolis Heart Institute Foundation, Minneapolis, Minnesota. Manuscript received March 10, 2010; manuscript received and accepted June 9, 2010.

This work was supported by Ministero Istruzione Università e Ricerca (PRin), Rome, Italy, the European Union (STREP Project 241577 "BIG HEART," Seventh European Framework Program), Brussels, Belgium, and the Hearst Foundations, New York, New York.

*Corresponding author: Tel: (+39) 04-4422-5111; fax: (+39) 0444225-5199.

E-mail address: snistr@tin.it (S. Nistri). position. ${ }^{3,4}$ However, we considered the possibility that the activity level at which the dynamic gradients are generated during exertion might affect the patient's exercise capacity. Therefore, in the present study, we revisited the issue of physiologically induced outflow gradients in $\mathrm{HC}$ with serial measurements made during symptom-limited upright bicycle exercise testing to determine whether the timing of gradient onset during exercise is of clinical relevance in patients with $\mathrm{HC}$.

\section{Methods}

The study group included 74 patients with HC but without LV outflow tract obstruction at rest (basal outflow gradient $<30 \mathrm{~mm} \mathrm{Hg}$ ). They were consecutively studied at our institution using exercise echocardiography (Table 1). The mean patient age was $45 \pm 16$ years, and $53(72 \%)$ were men. Historically, most patients $(\mathrm{n}=70,95 \%)$ had no or only mild exertional symptoms (Table 1). The clinical diagnosis of $\mathrm{HC}$ was determined by the demonstration on the 2-dimensional echocardiogram of a hypertrophied and nondilated left ventricle (wall thickness $\geq 15 \mathrm{~mm}$ ) in the absence of another cardiac or systemic disease capable of producing a similar degree of hypertrophy. ${ }^{5-7}$

Patients had their cardioactive medications withdrawn for $\geq 5$ half-lives before the exercise test and each had 
Table 1

Baseline clinical and exercise characteristics of study group and, separately, for 30 patients with hypertrophic cardiomyopathy (HC) with provokable obstruction according to early ( $\leq 5$ METs) or late ( $>5$ METs) onset of exercise-induced left ventricular (LV) outflow gradients of $\geq 30 \mathrm{~mm} \mathrm{Hg}$

\begin{tabular}{|c|c|c|c|c|}
\hline \multirow[t]{2}{*}{ Variable } & \multirow[t]{2}{*}{$\begin{array}{l}\text { Overall HC Cohort } \\
\qquad(\mathrm{n}=74)\end{array}$} & \multicolumn{2}{|c|}{$\begin{array}{l}\text { Patients With Inducible Gradient } \\
\qquad(\mathrm{n}=30)\end{array}$} & \multirow[t]{2}{*}{$\mathrm{p}$ Value } \\
\hline & & $\begin{array}{c}\text { Early } \\
(\mathrm{n}=16)\end{array}$ & $\begin{array}{c}\text { Late } \\
(\mathrm{n}=14)\end{array}$ & \\
\hline Age (years) & $45 \pm 16$ & $42 \pm 18$ & $40 \pm 15$ & 0.64 \\
\hline New York Heart Association functional class & $1.4 \pm 0.6$ & $1.5 \pm 0.6$ & $1.3 \pm 0.6$ & 0.35 \\
\hline Class I & $49(67 \%)$ & $9(57 \%)$ & $11(79 \%)$ & \\
\hline Class II & $21(28 \%)$ & $6(37 \%)$ & $2(14 \%)$ & 0.35 (overall) \\
\hline Class III & $4(5 \%)$ & $1(6 \%)$ & $1(7 \%)$ & \\
\hline Men & $53(72 \%)$ & $13(81 \%)$ & $13(93 \%)$ & 0.60 \\
\hline Left atrial diameter $(\mathrm{mm})$ & $43 \pm 7$ & $44 \pm 7$ & $46 \pm 8$ & 0.61 \\
\hline Left atrial volume index $\left(\mathrm{ml} / \mathrm{m}^{2}\right)$ & $48 \pm 12$ & $52 \pm 13$ & $54 \pm 19$ & 0.82 \\
\hline Left ventricular end-diastolic diameter ( $\mathrm{mm})$ & $44 \pm 5$ & $44 \pm 4$ & $45 \pm 6$ & 0.49 \\
\hline Left ventricular volume index $\left(\mathrm{ml} / \mathrm{m}^{2}\right)$ & $62 \pm 14$ & $59 \pm 12$ & $67 \pm 15$ & 0.21 \\
\hline Maximum left ventricular wall thickness (mm) & $23 \pm 6$ & $23 \pm 8$ & $23 \pm 6$ & 0.84 \\
\hline Left ventricular mass index $\left(\mathrm{g} / \mathrm{m}^{2}\right)^{*}$ & $102 \pm 30$ & $146 \pm 69$ & $106 \pm 35$ & 0.28 \\
\hline \multicolumn{5}{|l|}{ Heart rate (beats/min) } \\
\hline At baseline & $69 \pm 12$ & $68 \pm 8$ & $66 \pm 7$ & 0.45 \\
\hline At peak exercise & $140 \pm 20$ & $134 \pm 23$ & $142 \pm 22$ & 0.33 \\
\hline Percentage of heart rate attained & $80 \pm 10$ & $76 \pm 13$ & $79 \pm 9$ & 0.42 \\
\hline \multicolumn{5}{|l|}{ Blood pressure at rest $(\mathrm{mm} \mathrm{Hg})$} \\
\hline Systolic & $122 \pm 16$ & $122 \pm 16$ & $116 \pm 15$ & 0.24 \\
\hline Diastolic & $77 \pm 11$ & $73 \pm 11$ & $73 \pm 7$ & 0.97 \\
\hline \multicolumn{5}{|l|}{ Blood pressure at peak exercise $(\mathrm{mm} \mathrm{Hg})$} \\
\hline Systolic & $167 \pm 29$ & $158 \pm 24$ & $162 \pm 23$ & 0.67 \\
\hline Diastolic & $91 \pm 13$ & $89 \pm 11$ & $87 \pm 10$ & 0.61 \\
\hline \multicolumn{5}{|l|}{ Left ventricular outflow tract peak velocity $(\mathrm{m} / \mathrm{s})^{\dagger}$} \\
\hline At rest & $1.6 \pm 0.5$ & $1.9 \pm 0.5$ & $1.7 \pm 0.4$ & 0.25 \\
\hline At peak exercise & $3.0 \pm 1.3$ & $4.5 \pm 1.2$ & $4.1 \pm 0.8$ & 0.33 \\
\hline \multicolumn{5}{|l|}{ Left ventricular outflow tract gradient $(\mathrm{mm} \mathrm{Hg})^{\dagger}$} \\
\hline At peak exercise & $42 \pm 38$ & $86 \pm 44$ & $70 \pm 28$ & 0.24 \\
\hline \multicolumn{5}{|l|}{ Mitral regurgitation } \\
\hline At baseline & $0.6 \pm 0.5$ & $0.8 \pm 0.6$ & $0.7 \pm 0.6$ & 0.71 \\
\hline At peak exercise & $1.0 \pm 0.9$ & $1.8 \pm 0.9$ & $1.9 \pm 0.53$ & 0.72 \\
\hline Exercise capacity (METs) & $6.3 \pm 1.7$ & $6.1 \pm 1.3$ & $8.0 \pm 1.6$ & $<0.01$ \\
\hline
\end{tabular}

* Available for 48 of 74 study patients by cardiac magnetic resonance.

${ }^{\dagger}$ Measured with patient in upright position.

* Graded as none or trivial $(0)$, mild $(1+)$, moderate $(2+)$, or severe $(3+)$.

fasted $>4$ hours before the test. The patients performed maximum, symptom-limited exercise tests on a bicycle ergometer in the upright position. The exercise began at an initial workload of $25 \mathrm{~W}$, with stepwise $25-\mathrm{W}$ increments every 2 minutes. A 12-lead electrocardiogram was monitored continuously and recorded at baseline and at each minute during exercise and after exercise. The arterial blood pressure was measured using a mercury sphygmomanometer at baseline and every 2 minutes during exercise and in the postexercise phase. The patients were encouraged to perform maximally to achieve their expected heart rate. The maximum predicted heart rate was calculated as 220 minus the patient's age, and the percentage of the predicated heart rate was calculated as follows: (maximum heart rate attained/maximum predicated heart rate) $\times$ 100. Exercise was terminated when the predicted heart rate was achieved or when fatigue, dyspnea, chest pain, or hypotension intervened.

Peak exercise was defined as the maximum attained workload before discontinuation. The peak functional ca- pacity was estimated as METs, with one MET defined as the energy expended at rest, equivalent to an oxygen consumption of $3.5 \mathrm{ml} / \mathrm{kg}$ of body weight per minute, as recommended. ${ }^{8}$ No adverse events or clinically relevant arrhythmias occurred during exercise testing.

Standard echocardiographic studies were performed with the patient in the left lateral supine decubitus position using commercially available instruments according to current guidelines. ${ }^{9}$ The magnitude and distribution of LV hypertrophy was assessed, as previously described. ${ }^{10,11}$ Subaortic obstruction was defined as mechanical impedance to outflow due to systolic anterior motion with mitral valveventricular septal contact in midsystole ${ }^{7,12,13}$ and graded semiquantitatively, as previously described. ${ }^{14}$ The peak instantaneous LV outflow tract gradients were measured at rest (and with the Valsalva maneuver) with the patient in the left lateral position with continuous-wave Doppler interrogation in the apical 5-chamber view. We took care to avoid contamination of the waveform by the mitral regurgitation jet. ${ }^{1,3}$ Mitral regurgitation was graded as 


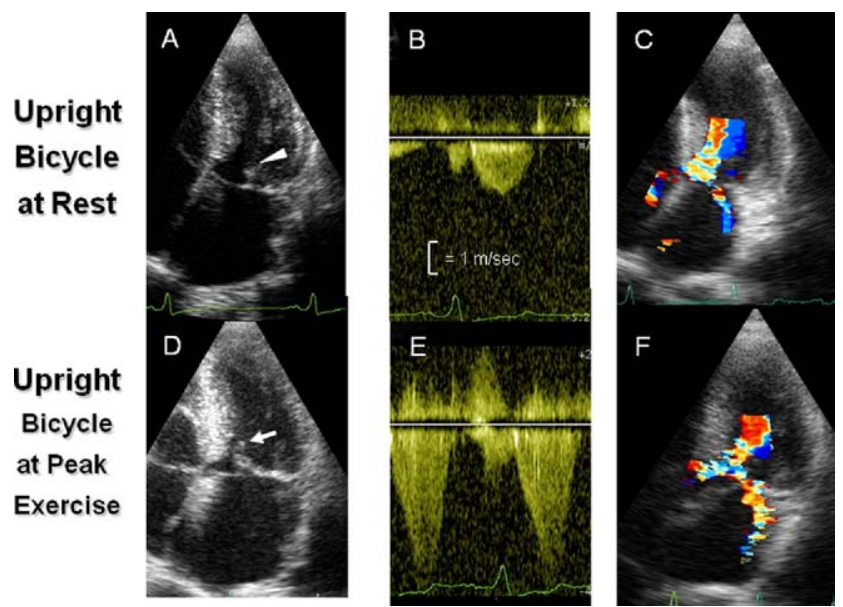

Figure 1. Exercise-induced obstruction in patients with HC. (A) Apical 5-chamber long-axis view at end-systole with only mild systolic anterior motion (SAM) (arrowhead), (B) continuous-wave Doppler image showing normal LV outflow tract velocity $(1.8 \mathrm{~m} / \mathrm{s})$, and $(C)$ SAM-related posteriorly directed mild mitral regurgitation jet; all images obtained at rest. (D) SAM with septal contact (arrow), (E) corresponding continuous-wave Doppler velocity of $5 \mathrm{~m} / \mathrm{s}$ (i.e., $100-\mathrm{mm} \mathrm{Hg}$ gradient), and $(F)$ substantial increase in magnitude of mitral regurgitation; all obtained at peak exercise in identical view.

none or trivial $(0)$, mild $(1+)$, moderate $(2+)$, and severe $(3+)$.

Echocardiography was performed with the patients sitting upright on the bicycle ergometer under basal conditions and serially every 2 minutes during exercise at each $25-\mathrm{W}$ workload increase, with $9 \pm 3$ measurements/patient (range 4 to 12). The left ventricle was imaged in the apical and parasternal long-axis views to identify and grade the systolic anterior motion and mitral regurgitation and to estimate the LV outflow tract gradient using continuous-wave Doppler echocardiography. After termination of the exercise, the patients were immediately placed in the left lateral decubitus position, and the LV outflow tract velocities were measured again in the apical view using continuous-wave Doppler echocardiography.

For the purposes of the present study, the exercise-induced gradients were considered clinically relevant when $\geq 30 \mathrm{~mm} \mathrm{Hg}$. The onset of outflow obstruction during exercise was regarded as early when it occurred at a workload of $\leq 5$ METs and late at a workload of $>5$ METs. ${ }^{8}$

The data are expressed as the mean $\pm \mathrm{SD}$. The paired Student $t$ test or one-way analysis of variance was used to compare normally distributed data. The chi-square test (and where applicable, Yate's corrected chi-square test) was used to compared noncontinuous variables, expressed as proportions. The predictors of marked exercise-inducing obstruction were assessed by multivariate logistic regression analysis. $p$ Values $<0.05$ were considered significant. Calculations were performed using the Statistical Package for Social Sciences, version 12.0 (SPSS, Chicago, Illinois).

\section{Results}

Data were obtained for 74 patients with $\mathrm{HC}$ with a LV outflow gradient of $<30 \mathrm{~mm} \mathrm{Hg}$ at rest in the supine

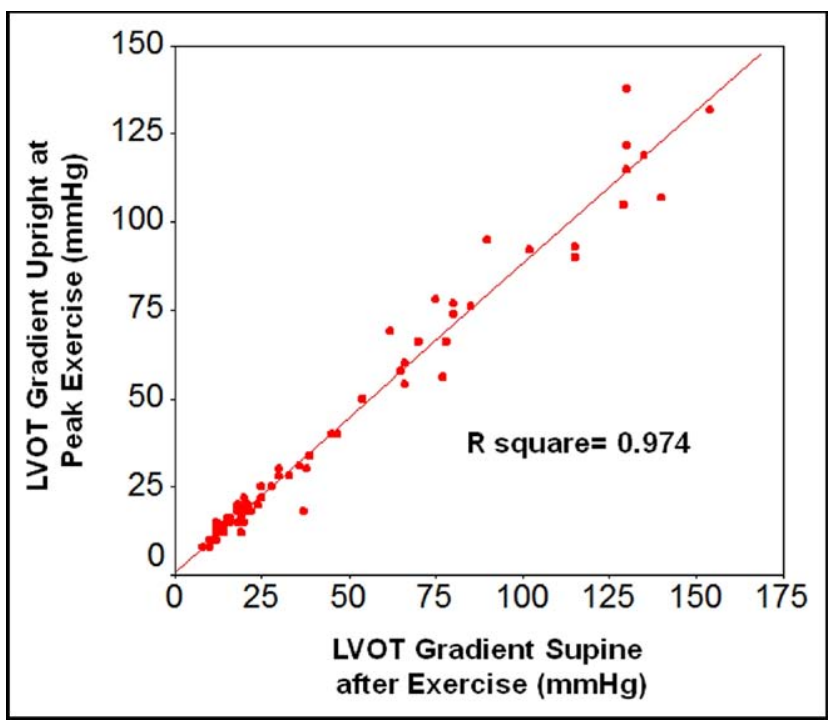

Figure 2. Comparison of upright versus supine provokable LV outflow gradients. Scatterplot of gradients measured at peak exercise with patient in upright position (ordinate) and after exercise in supine position (abscissa), showing excellent correlation between both measurements. LVOT $=\mathrm{LV}$ outflow tract.

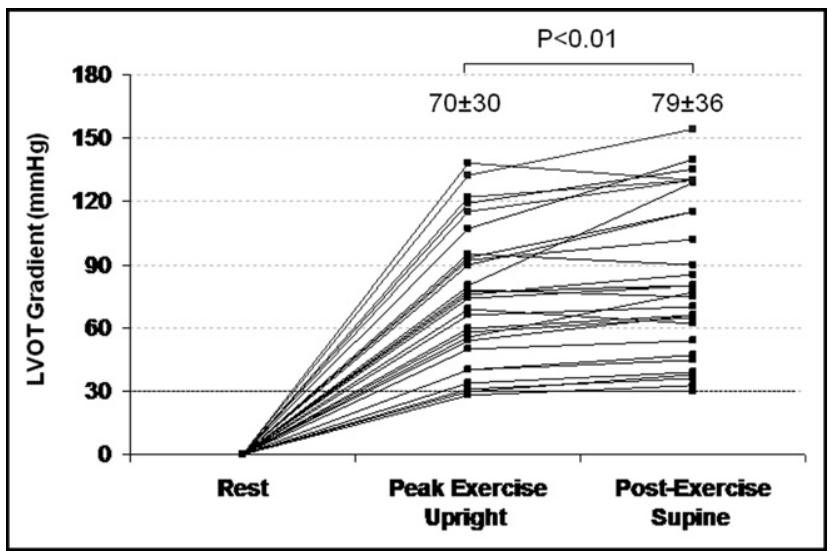

Figure 3. Individual gradient variations in patients with $\mathrm{HC}$ with provokable obstruction. Changes in LV outflow tract gradient from at rest (basal) conditions to at peak upright exercise with patient in supine position immediately after exercise. Shown for 30 patients with $\mathrm{HC}$ with inducible gradients of $\geq 30 \mathrm{~mm} \mathrm{Hg}$. Each line connects 3 intervals of the test for individual patients. At baseline, LV outflow gradient was considered 0, because systolic anterior motion of mitral valve was mild or absent, excluding mechanical impedance to flow.

position and erect on a cycle ergometer (Table 1). Of the 74 patients, $24(32 \%)$ attained $>85 \%$ of their maximum predicated heart rate, and $50(68 \%)$ achieved submaximum target heart rates and terminated the test because of fatigue $(\mathrm{n}=40)$, and/or dyspnea $(\mathrm{n}=26)$, and/or a systolic blood pressure decrease of $>25 \mathrm{~mm} \mathrm{Hg}$ during exercise $(\mathrm{n}=4)$.

Of the 74 study patients, $30(40 \%)$ developed dynamic $\mathrm{LV}$ outflow tract gradients of $\geq 30 \mathrm{~mm} \mathrm{Hg}$ during exercise because of systolic anterior motion and mitral-septal contact (Figure 1). The remaining 44 patients $(60 \%)$ remained at less than the $30-\mathrm{mm} \mathrm{Hg}$ gradient threshold.

The LV outflow tract gradients measured with the patients upright at peak exercise were slightly lower than those 


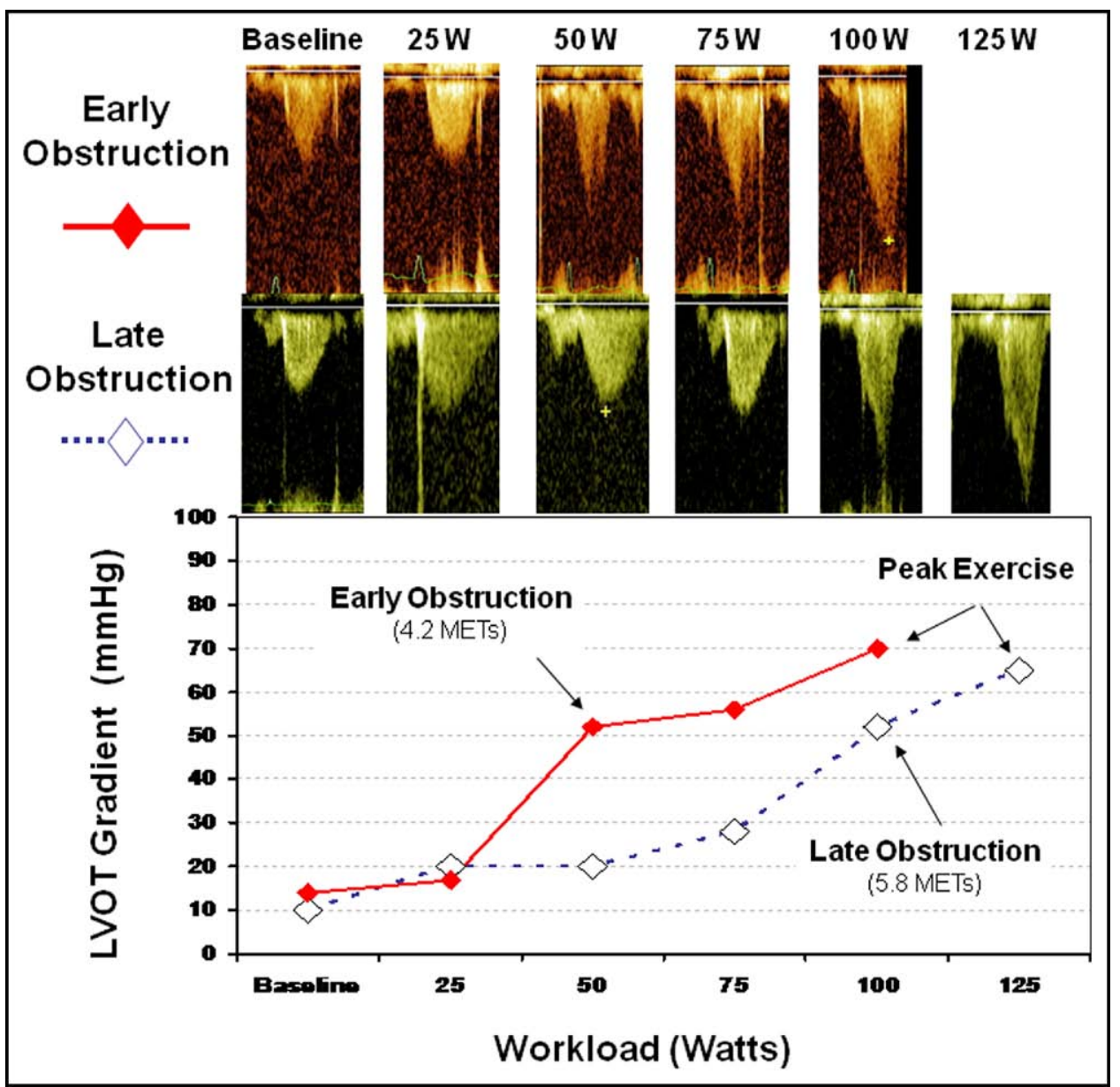

Figure 4. Patterns of gradient provocation with exercise. In a 45-year-old patient with early obstruction (solid line and red squares), a 55-mm Hg inducible gradient was measured at $50 \mathrm{~W}$ (4.2 METs). Exercise was terminated at $100 \mathrm{~W}$ (5.8 METs) because of dyspnea associated with a peak upright gradient of $70 \mathrm{~mm} \mathrm{Hg}$; the peak postexercise supine gradient was $87 \mathrm{~mm} \mathrm{Hg}$. In a 47-year-old patient with late obstruction (broken line and white squares), a 52 -mm $\mathrm{Hg}$ gradient was induced at $100 \mathrm{~W}(5.8 \mathrm{METs})$. Exercise was terminated at $125 \mathrm{~W}$ (78.5 METs) because of fatigue when the gradient had increased to 65 $\mathrm{mm} \mathrm{Hg}$; peak postexercise supine gradient was $85 \mathrm{~mm} \mathrm{Hg}$.

obtained with them placed supine immediately after exercise $(39 \pm 35$ vs $44 \pm 40 \mathrm{~mm} \mathrm{Hg}$, respectively; $\mathrm{p}<0.01)$. Nevertheless, the correlation between the 2 measurements was high $\left(\mathrm{R}^{2}=0.974\right)$, with small absolute individual differences (average $5 \pm 7 \mathrm{~mm} \mathrm{Hg}$; Figure 2).

For the 30 patients with provoked obstruction, the gradient was $70 \pm 30 \mathrm{~mm} \mathrm{Hg}$ at peak exercise and $79 \pm 36 \mathrm{~mm}$ $\mathrm{Hg}$ immediately after exercise $(\mathrm{p}<0.01)$, with absolute individual differences averaging $10 \pm 8 \mathrm{~mm} \mathrm{Hg}$ (range 0 to 33; Figure 3). These gradients were reached during exercise at $4.6 \pm 1.7$ METs (range 2.1 to 6.9 ). In 29 of the 30 patients, the gradients exceeded $\geq 30 \mathrm{~mm} \mathrm{Hg}$ both at peak exercise and in recovery. The exception was a 65 -year-old woman with a peak gradient of $28 \mathrm{~mm} \mathrm{Hg}$ in the upright position and $33 \mathrm{~mm} \mathrm{Hg}$ in the supine position. In addition, each of the 22 patients achieving a gradient of $\geq 50 \mathrm{~mm} \mathrm{Hg}$ in the supine position had exceeded the same threshold in the upright measurements (Figure 3).

Two patterns of LV outflow tract gradient onset were identified according to the predetermined criteria (Figure 4): early obstruction (development of $\geq 30$-mm $\mathrm{Hg}$ gradients at $\leq 5$ METs) was observed in 16 patients, and late obstruction (development at $>5$ METs) was observed in 14 patients (Table 1). Compared to patients with late obstruction, the patients with early obstruction had a reduced exercise capacity $(6.1 \pm 1.3$ vs $8.0 \pm 1.6 \mathrm{METs}, \mathrm{p}<0.01)$. This finding was not predictable from the baseline clinical and echocardiographic features, peak exercise LV outflow tract gradients, percentage of the predicted maximum heart rate, severity of mitral regurgitation at peak exercise, or New York Heart Association functional class (Table 1).

Compared to patients without provoked gradients of $\geq 30$ $\mathrm{mm} \mathrm{Hg}$, those with provocable gradients were more often men $(87 \%$ vs $61 \%, p=0.02)$, had a larger left atrial size $(45 \pm 7$ vs $41 \pm 7 \mathrm{~mm}, \mathrm{p}=0.045)$, and greater $L V$ outflow tract velocities at rest $(1.8 \pm 0.5$ vs $1.4 \pm 0.3 \mathrm{~m} / \mathrm{s}, \mathrm{p}=$ $0.002)$. On multivariate logistic regression analysis, the independent predictors of exercise-induced obstruction were male gender (hazard ratio 4.0, 95\% confidence interval 1.1 to $14.4, \mathrm{p}=0.036$ ), greater at rest $\mathrm{LV}$ outflow tract velocity (hazard ratio 1.23 for each $10 \mathrm{~cm} / \mathrm{s}$ increase, $95 \%$ CI 1.07 to $1.42, \mathrm{p}=0.0043$ ), and lower resting diastolic blood pressure (hazard ratio 0.93 for each $1-\mathrm{mm} \mathrm{Hg}$ increase, $95 \% \mathrm{CI}$ 0.89 to $0.99, \mathrm{p}=0.027$ ). 


\section{Discussion}

To achieve an enhanced understanding of the pathophysiology of exercise-induced LV outflow obstruction in patients with $\mathrm{HC}$, we devised the present study protocol according to a serial gradient assessment at each step of a symptom-limited upright bicycle exercise test. We found that this strategy provided important information not available using a single gradient measurement at peak exercise or in the immediate recovery period. With real-time monitoring of the LV outflow tract velocities during physiologic exercise, we were able to show that the timing of the onset of obstruction dictated the degree to which exercise capacity was impaired in patients with $\mathrm{HC}$ and provokable gradients.

Of the 30 patients who developed LV outflow obstruction of $\geq 30 \mathrm{~mm} \mathrm{Hg}$ during exercise, about $50 \%$ did so early at low workloads ( $\leq 5 \mathrm{METs}$ ), suggesting that substantial impedance to outflow might be produced, even during routine daily activities, and impose an hemodynamic burden on LV function. ${ }^{15}$ The other $50 \%$, however, achieved the same degree of obstruction with moderate-to-high workloads, equivalent to a greater intensity of physical activity such as might be attained during sports or manual work. These differences in the timing of provoked obstruction had a direct effect on the exercise performance exhibited by our patients. Despite similar baseline clinical and echocardiographic features, and physiologically provoked gradients of a similar magnitude, the patients with early development of outflow obstruction during exercise performed at a lower level than those who developed obstruction later during exercise. Specifically, those patients with early gradients achieved an average of 6.1 METs at peak exercise, representing absolute impairment in functional capacity ${ }^{8,16}$ compared to an average of 8.0 METs in the patients with late obstruction. Such differences place the $2 \mathrm{HC}$ subsets in substantially different risk categories for all-cause and cardiovascular mortality, using evidence from non-HC patients and from the general population. ${ }^{17-19}$ For example, in the recent study by Kokkinos et al, ${ }^{20}$ demonstrating a strong inverse association between exercise capacity and all-cause mortality in $>4,000$ prehypertensive subjects, the $\leq 6$ METs threshold identified subjects at a low fitness level and increased risk. By extrapolation, it is possible that the reduction in exercise performance associated with the early development of outflow obstruction might prove relevant to long-term disease progression in patients with HC. The present analysis, cross-sectional in study design and largely of patients with no or only mild symptoms, did not allow us to draw firm conclusions in this regard. Because of the characteristic slow progression of the $\mathrm{HC}$ disease process, extended follow-up periods of larger groups of patients are necessary to achieve sufficient statistical power and examine the significance of provocable outflow gradient on heart failure progression and outcome.

Our findings might have potential implications for patient treatment, supporting the view that the assessment of LV outflow gradients during exercise, which is generally not performed in clinical practice, should be selectively considered for patients with HC. For those patients capable of physiologically provoking outflow obstruction, the level of recommended working or leisure-time physical activity can be tailored to the results of the exercise test, by advising patients to maintain a maximum heart rate at less than the level at which the gradient was initially generated.

Furthermore, for patients with $\mathrm{HC}$ with heart failurerelated functional disability secondary to outflow obstruction induced by exercise, $\beta$ blockers have an accepted role in controlling symptoms. ${ }^{3}$ Also, $\beta$-blocking agents are known to have the capability of blunting outflow gradients provoked physiologically (by exercise). ${ }^{21}$ Although largely speculative at this time, we believe a potentially beneficial use could exist for $\beta$ blockers in HC (even for asymptomatic patients) to normalize LV pressure and wall stress, which over time could promote heart failure symptoms and alter the natural disease course. In this regard, serial exercise echocardiography could be proposed for longitudinal assessment of the efficacy of such pharmacologic therapy on gradient-generation capacity and exercise tolerance. ${ }^{22}$

Finally, we found substantial agreement between the magnitude of outflow gradients measured at the final step of the exercise test in the upright position and those gradients obtained with the patients in the supine position immediately after exercise. Specifically, all but 1 of the 30 patients with gradients of $\geq 30 \mathrm{~mm} \mathrm{Hg}$, and all those gradients of $\geq 50 \mathrm{~mm} \mathrm{Hg}$, in the supine position also exceeded the same thresholds in the upright measurements. Observed individual discrepancies were relatively minor, with postexercise supine gradients overestimating somewhat the upright gradients an average of $5 \mathrm{~mm} \mathrm{Hg}$ for the study group. These differences could have been related to a reduction in the LV outflow tract area by the combination of a sudden reduction in venous return during recovery, coupled with a persistently low peripheral resistance and continued sympathetic drive. ${ }^{4,23,24}$ Moreover, potential technical factors could be in play, including recognition that alignment of the ultrasound cursor in the LV outflow tract might be more reliable after the cessation of exercise with reduced chest movement.

Our findings differ from those of 2 other studies, ${ }^{25,26}$ which suggested a substantial underestimation of gradients assessed with the patient supine in the recovery period after treadmill exercise testing compared to those detected upright. However, such patients were assessed while receiving active treatment with $\beta$ blockers or verapamil, or both, which could have substantially blunted the magnitude and altered the course of the inducible obstruction. Such heterogeneous results might also underscore the extremely dynamic degree of LV outflow obstruction that can be observed in individual patients. ${ }^{27}$ Nevertheless, the present results, obtained during physiologic exercise and during a pharmacologic "wash-out," have shown that it is equally acceptable to use either the upright or postexercise supine technique to assess the magnitude of inducible obstruction in patients with $\mathrm{HC}$ for clinical purposes. ${ }^{3}$

1. Maron MS, Olivotto I, Betocchi S, Casey SA, Lesser JR, Losi MA, Cecchi F, Maron BJ. Effect of left ventricular outflow tract obstruction on clinical outcome in hypertrophic cardiomyopathy. $N$ Engl J Med 2003;348:295-303.

2. Autore C, Bernabo P, Barilla CS, Bruzzi P, Spirito P. The prognostic importance of left ventricular outflow obstruction in hypertrophic cardiomyopathy varies in relation to the severity of symptoms. $J \mathrm{Am}$ Coll Cardiol 2005;45:1076-1080. 
3. Maron MS, Olivotto I, Zenovich AG, Link MS, Pandian NG, Kuvin JT, Nistri S, Cecchi F, Udelson JE, Maron BJ. Hypertrophic cardiomyopathy is predominantly a disease of left ventricular outflow tract obstruction. Circulation 2006;114:2232-2239.

4. Shah JS, Esteban MT, Thaman R, Sharma R, Mist B, Pantazis A, Ward D, Kohli SK, Page SP, Demetrescu C, Sevdalis E, Keren A, Pellerin D, McKenna WJ, Elliott PM. Prevalence of exercise-induced left ventricular outflow tract obstruction in symptomatic patients with non-obstructive hypertrophic cardiomyopathy. Heart 2008;94:1288-1294.

5. Vaglio JC Jr, Ommen SR, Nishimura RA, Tajik AJ, Gersh BJ. Clinical characteristics and outcomes of patients with hypertrophic cardiomyopathy with latent obstruction. Am Heart J 2008;156:342-347.

6. Nishimura RA, Ommen SR. Hypertrophic obstructive cardiomyopathy: the search for obstruction . Circulation 2006;114:2200-2202.

7. Maron BJ, McKenna WJ, Danielson GK, Kappenberger LJ, Kuhn HJ, Seidman CE, Shah PM, Spencer WH, Spirito P, ten Cate FJ, Wigle ED. American College of Cardiology/European Society of Cardiology Clinical Expert Consensus Document on Hypertrophic Cardiomyopathy: a report of the American College of Cardiology Task Force on Clinical Expert Consensus Documents and the European Society of Cardiology Committee for Practice Guidelines Committee to Develop an Expert Consensus Document on Hypertrophic Cardiomyopathy. J Am Coll Cardiol 2003;42:1687-1713.

8. Fletcher GF, Balady GJ, Amsterdam EA, Chaitman B, Eckel R, Fleg J, Froelicher VF, Leon AS, Piña IL, Rodney R, Simons-Morton DA, Williams MA, Bazzarre T. Exercise standards for testing and training: a statement for healthcare professionals from the American Heart Association. Circulation 2001;104:1694-1740.

9. Lang RM, Bierig M, Devereux RB, Flachskampf FA, Foster E, Pellikka PA, Picard MH, Roman MJ, Seward J, Shanewise JS, Solomon SD, Spencer KT, Sutton MS, Stewart WJ; Chamber Quantification Writing Group; American Society of Echocardiography's Guidelines and Standards Committee; European Association of Echocardiography. Recommendations for chamber quantification: a report from the American Society of Echocardiography's Guidelines and Standards Committee and the Chamber Quantification Writing Group, developed in conjunction with the European Association of Echocardiography, a branch of the European Society of Cardiology. J Am Soc Echocardiogr 2005;18:1440-1463.

10. Spirito $\mathrm{P}$, Bellone $\mathrm{P}$, Harris KM, Bernabo $\mathrm{P}$, Bruzzi $\mathrm{P}$, Maron BJ. Magnitude of left ventricular hypertrophy predicts the risk of sudden death in hypertrophic cardiomyopathy. N Engl J Med 2000;342:17781785.

11. Klues HG, Schiffers A, Maron BJ. Phenotypic spectrum and patterns of left ventricular hypertrophy in hypertrophic cardiomyopathy: morphologic observations and significance as assessed by two-dimensional echocardiography in 600 patients. J Am Coll Cardiol 1995;26: 1699-1708.

12. Shah PM, Gramiak R, Adelman AG, Wigle ED. Echocardiographic assessment of the effects of surgery and propranolol on the dynamics of outflow obstruction in hypertrophic subaortic stenosis. Circulation 1972;45:516-521.
13. Sherrid MV, Chu K, Delia E, Mogtaded A, Dwyer EM Jr. An echocardiographic study of the fluid mechanics of obstruction in hypertrophic cardiomyopathy. J Am Coll Cardiol 1993;22:816-824.

14. Gilbert BW, Pollick C, Adelman AG, Wigle ED. Hypertrophic cardiomyopathy: subclassification by M-mode echocardiography. Am J Cardiol 1980;45:861-871.

15. Levine RA, Jimoh A, Cape EG, McMillan S, Yoganathan AP, Weyman AE. Pressure recovery distal to a stenosis: potential cause of gradient "overestimation" by Doppler echocardiography. J Am Coll Cardiol 1989;13:706-715.

16. Kokkinos P, Myers J, Kokkinos JP, Pittaras A, Narayan P, Manolis A, Karasik P, Greenberg M, Papademetriou V, Singh S. Exercise capacity and mortality in white and black men. Circulation 2008;117:614-622.

17. Myers J, Prakash M, Froelicher V, Do D, Partington S, Atwood JE. Exercise capacity and mortality among men referred for exercise testing. N Engl J Med 2002;346:793-801.

18. Peterson PN, Magid, DJ, Ross C, Ho PM, Rumsfeld JS, Lauer MS, Lyons EE, Smith SS, Masoudi FA. Association of exercise capacity on treadmill with future cardiac events in patients referred for exercise testing. Arch Intern Med 2008;168:174-179.

19. Kodama S, Saito K, Tanaka S, Maki M, Yachi Y, Asumi M, Sugawara A, Totsuka K, Shimano H, Ohashi Y, Yamada N, Sone H. Cardiorespiratory fitness as a quantitative predictor of all-cause mortality and cardiovascular events in healthy men and women: a meta-analysis. JAMA 2009;301:2024-2035.

20. Kokkinos P, Myers J, Doumas M, Faselis C, Manolis A, Pittaras A, Kokkinos JP, Singh S, Fletcher RD. Exercise capacity and all-cause mortality in prehypertensive men. Am J Hypertens 2009;22:735-741.

21. Braunwald E, Lambrew CT, Rockoff SD, Ross J Jr, Morrow AG Idiopathic hypertrophic subaortic stenosis. I. A description of the disease based upon an analysis of 64 patients. Circulation 1964; 30(Suppl IV):3-119.

22. Ommen SR, Shah PM, Tajik AJ. Left ventricular outflow tract obstruction in hypertrophic cardiomyopathy: past, present and future. Heart 2008;94:1276-1281.

23. Schwammenthal E, Schwartzkopff B, Block M, Johns J, Lösse B, Engberding R, Borggrefe M, Breithardt G. Doppler echocardiographic assessment of the pressure gradient during bicycle ergometry in hypertrophic cardiomyopathy. Am J Cardiol 1992;69:1623-1628.

24. Klues HG, Leuner C, Kuhn H. Left ventricular outflow tract obstruction in patients with hypertrophic cardiomyopathy: increase in gradient after exercise. J Am Coll Cardiol 1992;19:527-533.

25. Dimitrow PP, Bober M, Michałowska J, Sorysz D. Left ventricular outflow tract gradient provoked by upright position or exercise in treated patients with hypertrophic cardiomyopathy without obstruction at rest. Echocardiography 2009;26:513-520.

26. Miranda R, Cotrim C, Cardim N, Almeida S, Lopes L, Loureiro MJ, Simões O, Cordeiro P, Fazendas P, João I, Carrageta M. Evaluation of left ventricular outflow tract gradient during treadmill exercise and in recovery period in orthostatic position, in patients with hypertrophic cardiomyopathy. Cardiovasc Ultrasound 2008;15:6:19.

27. Geske JB, Sorajja P, Ommen SR, Nishimura RA. Left ventricular outflow tract gradient variability in hypertrophic cardiomyopathy. Clin Cardiol 2009;32:397-402. 